\title{
When Will the Next El Niño Occur?
}

\author{
David Holmes Douglass \\ Department of Physics and Astronomy, University of Rochester, Rochester, USA \\ Email: douglass@pas.rochesrer.edu
}

How to cite this paper: Douglass, D.H. (2018) When Will the Next El Niño Occur? Atmospheric and Climate Sciences, 8, 431434. https://doi.org/10.4236/acs.2018.84028

Received: October 2, 2018

Accepted: October 27, 2018

Published: October 30, 2018

Copyright $\odot 2018$ by author and Scientific Research Publishing Inc. This work is licensed under the Creative Commons Attribution International License (CC BY 4.0).

http://creativecommons.org/licenses/by/4.0/

\begin{abstract}
There is great interest in knowing when a future El Niño will occur. Most physical models forecast the future based on climate data from the recent past-about a year. The forecasted future is also a fraction of a year. This approach to predicting the future does not use the fact that the climate system may be in a phase-locked state in which sinusoidal oscillations of 2 or 3 years are observed. These states can last many cycles. Thus, if the climate system is in a phase-locked state, one may be able to make definite statements about the future independent of physical models. Douglass, Knox, Curtiss, Geise and Ray (DKCGR) have used the fact that the climate system is presently in a phase-loxked state of period 3 years to state (December 2016) that the next El Niño episode may show a maximum at about November of 2018. We present an updated analysis and state (September 2018) that if the climate system remains in a phase-locked state of period 3 years there will be an El Niño maximum at about November 2018. If that happens, there could be another El Niño maximum at about November 2021.
\end{abstract}

\section{Keywords}

Climate Shifts, Climatology, El Niño, Phase Locking

\section{Introduction}

The climate phenomenon known as El Niño is of great interest. See Philander [1]. A recent detailed study was published by Douglass, Knox, Curtis, Giese and Ray (DKCGR) [2] who studied the central Pacific sea surface temperature (SST) index SST3.4, which was introduced by Barnston et al. [3] and is commonly used as a proxy to study the El Niño/La Niña phenomena.

DKCGR found 18 distinct time segments of SST3.4 that showed sinusoid-like oscillations of period 2 or 3 years. The periodicities ( 2 or 3 years) and duration of these phase-locked segments were determined by the autocorrelation method (AM). In this method, if the time segment contains a periodic signal then the 
delayed autocorrelation function of the signal will show a maximum at a delay equal to the period. The ends of the phase-locked segments are also determined. In addition, the end dates are close to the dates of climate shifts reported in [4]. The reason for the climate shifts is not known although Douglass [5] has suggested that the phase-locked sates may have upper and lower stability limits similar to the stability limits of the subharmonics of the 1-D nonlinear harmonic oscillator. See [6]. These oscillations are associated with the subharmonics of a climate forcing of Solar origin. Also, DKCGR defined an El Niño as the positive maximum of the anomaly index aSST3.4 (see next section) and found that the El Niños all were in these phase-locked segments. A total of 40 El Niño episodes since 1872 were found. Their list included all prior reports of El Niños.

El Niño episode 40 is in a phase-locked state of period 3 years and as of this date (September 2018) is ongoing.

Note: A link to the DKCGR paper is given at the end of the references.

\section{Data}

The basic data is the same SST3.4 as in DKCGR. One needs to create an anomaly index from SST3.4; Barnston et al. [3] created an anomaly index Nino3.4 by the "climatology method". However, it was shown that Nino3.4 contains false signals and a better anomaly index was created [7]. The first step is to remove the strong annual signal. This is achieved by applying a 12-month digital running average filter to SST3.4. This filter removes not only the annual signal, but also the harmonics. The particular filter used is a 6-1-5 filter where the center is on the "1".

An anomaly aSST3.4 is created by subtracting a 30-year average of SST3.4. From its definition the index aSST3.4 ends (March 2018) before the end (August 2018) of SST3.4.

How can the information in the 5 data valises be beyond to extend aSST3.4? R. S. Knox has proposed a data series of 5 values beyond the end of aSST3.4 that he calls "tapered average," which uses fewer than 12 values in the average. Specifically, he bases the final five months on modified filtered data: each point is taken as the average of points ending at the latest point of SST3.4 and beginning at the point symmetrically before it. Example: the point 4th from the end is averaged starting with the point 7 th from the end. We will call this series aSST3.4_K.

The SST3.4 data may be downloaded at [8].

\section{The Most Recent Phase-Locked Segment}

DKCGR identified eighteen phase-locked segments, the last one (labeled segment 11) began in 2009.

Figure 1 shows aSST3.4 (red) from 2007 through March 2018 and the 5 vaues of the Knox index aSST3.4_K (see Sec. 2). This time interval includes sagment 11. In DKCGR it was reported that aSST3.4 entered a phase-locked state of period 3 years in early 2009. This phase-locked segment is labeled segment 11, in 


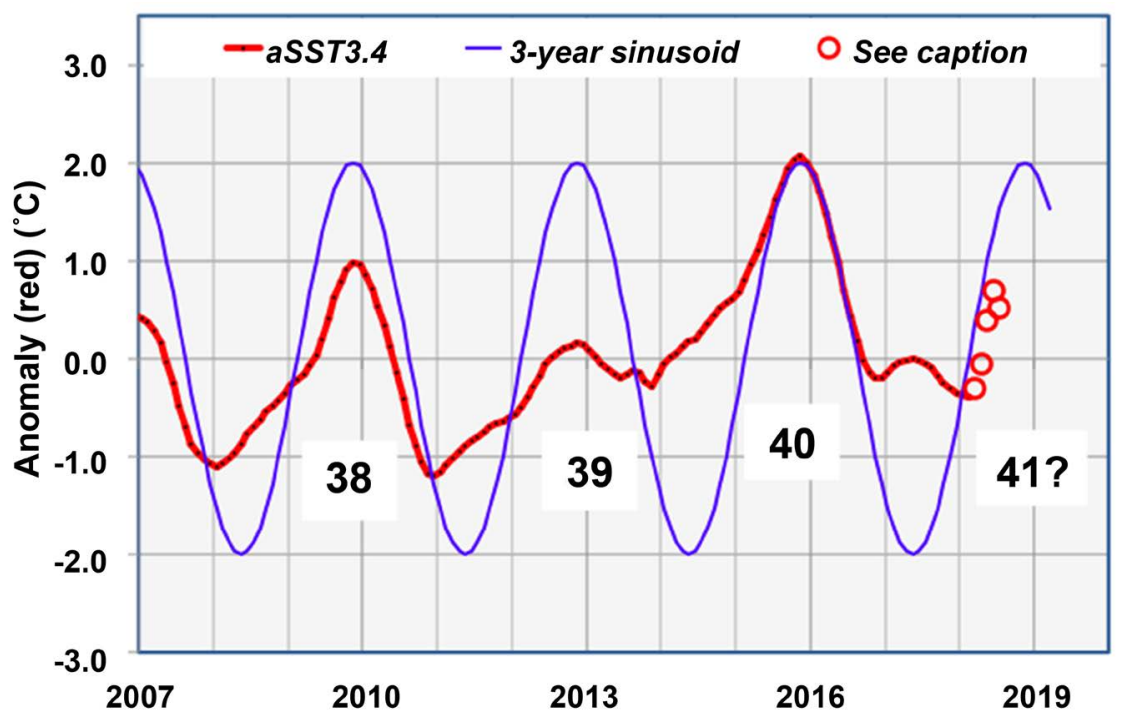

Figure 1. Update of the DKCGR data in aSST3.4 segment 11, showing the probable approach to a fourth El Niño in November 2018. Data for the solid red curve are 12-month centered running averages. The red circles are partially filtered (see Sec. 2). The blue curve is a sinusoid of period three years for reference.

which three maxima occur during November of 2009, 2012, and 2015. These 3 maxima are El Niño episodes 38, 39 and 40. If the phase-locked state in segment 11 persists then we would expect a 4th maximum (El Niño) during November of 2018.

Also shown is a sinusoid of period three years whose maximum was set at November. We note that aSST3.4 is periodic of period three years but the signal is not a pure sinusoid. One sees that the Knox data are increasing parallel to the sinusoid.

Will aSST3.4 show a 4th maximum (El Niño) at about November 2018? We will not know until SST3.4 data though to about February 2019 has been measured. We can say, however, that if a maximum (El Niño) occurs during November 2018, segment 11 continues and the possibly of a 5th El Niño during boreal winter of 2021 arises. Conversely, no maximum in November 2018 means the phase-locked state in segment 11 has certainly ended and a climate shift may well have occurred.

\section{Summary}

It was stated (in December 2016) by DKCGR: "If the climate system remains in this state, the next El Niño is likely to occur during boreal winter of 2018." As of this date (September 2018), it does appear that a 4th El Niño may occur then. If that happens, there could be a fifth El Niño maximum at about November 2021.

\section{Acknowledgements}

We had helpful comments from Scott Curtis. We are very thankful to R. S. Knox for creating the "tapered" average. 


\section{Conflicts of Interest}

The author declares no conflicts of interest regarding the publication of this paper.

\section{References}

[1] Philander, S. (2004) Our Affair with El Niño. Princeton University Press.

[2] Douglass, D.H., Knox, R.S., Curtis, S., Giese, B.S. and Ray, S. (2017) Historical Phase-Locked El Niño Episodes. Atmospheric and Climate Sciences, 7, 48-64. https://doi.org/10.4236/acs.2017.71005

[3] Barnston, A.C., Chelliah, M. and Goldenberg, S.B. (1997) Documentation of a Highly ENSO-Related sst Region in the Equatorial Pacific: Research Note. Atmosphere-Ocean, 35, 367. https://doi.org/10.1080/07055900.1997.9649597

[4] Douglass, D.H. (2010) Topology of Earth's Climate Indices and Phase-Locked States. Physics Letters A, 374, 4164-4168.

[5] Douglass, D.H. (2011) The Pacific Sea Surface Temperature. Physics Letters A, 376, 128-135. https://doi.org/10.1016/j.physleta.2011.10.042

[6] Stoker, J. (1950) Nonlinear Vibrations. Intercedence Publishers, NY.

[7] Douglass, D.H. (2011) Separation of a Signal of Interest from a Seasonal Effect in Geophysical Data: I. El Niño/LaNiña Phenomenon. International Journal of Geosciences, 2, 414-419. https://doi.org/10.4236/ijg.2011.24045

[8] NOAA/CPC: SST3.4 Indices. http://www.cpc.ncep.noaa.gov/data/indices/ 